\title{
FLORA DA SERRA DO CIPÓ, MINAS GERAIS: PTERIDACEAE - ADIANTOIDEAE E TAENITIDOIDEAE ${ }^{1}$
}

\author{
JEFFERSON PRADO
}

Instituto de Botânica, Seção de Briologia e Pteridologia. CP 4005. CEP 01061-970 - São Paulo, SP. (Bolsista do CNPq).

\begin{abstract}
Flora of the Serra do Cipó, Minas Gerais: Pteridaceae - Adiantoideae and Taenitidoideae). A floristic study of the subfamilies Adiantoideae and Taenitidoideae, as a contribution to the project "Flora of the Serra do Cipó, Minas Gerais, Brazil", is presented. In that region the subfamily Adiantoideae is represented by the genus Adiantum (2 species) and the subfamily Taenitidoideae by the genus Eriosorus (1 species). Description of the family, keys and descriptions of the subfamilies, genera and species, as well as illustrations, comments on the distribution, habitats and variability are presented.

Resumo - (Flora da Serra do Cipó, Minas Gerais: Pteridaceae - Adiantoideae e Taenitidoideae). É apresentado um estudo florístico das subfamílias Adiantoideae e Taenitidoideae, como uma contribuição ao projeto "Flora da Serra do Cipó, Minas Gerais, Brasil". Na região, a subfamília Adiantoideae é representada pelo gênero Adiantum (2 espécies) e a subfamília Taenitidoideae pelo gênero Eriosorus (1 espécie). São apresentadas descrição da família, chaves e descrições para subfamílias, gêneros e espécies, bem como ilustrações, comentários relativos à distribuição, habitat e variabilidade.
\end{abstract}

Key words: Pteridophyta, Pteridaceae, Adiantoideae, Taenitidoideae, ferns, Serra do Cipó floristics, Central-Brazilian rupestrial formations, "campos rupestres".

\section{Pteridaceae}

Plantas terrestres ou rupícolas. Caule com tricomas, cerdas ou escamas. Pina, pínula ou segmento fértil com a margem fortemente recurvada e modificada em indúsio ou margem plana, não modificada; venação aberta ou areolada. Soros marginais ou dispostos ao longo das nervuras, com ou sem paráfises; indúsio com ou sem nervuras ou indúsio ausente; esporos triletes, não clorofilados.

\section{Chave para as subfamílias}

1. Soros marginais, indúsio formado pela margem da lâmina delgada e recurvada 1. Adiantoideae 1'. Soros ao longo das nervuras, indúsio ausente 2. Taenitidoideae

\section{Adiantoideae (C. Presl) R. M. Tryon}

Caule com escamas. Pina, pínula ou segmento fértil com a margem fortemente recurvada, modificada em indúsios. Soros sobre lobos marginais recurvados, sem paráfises, indúsio provido de nervuras; esporos com os ângulos proeminentes, superfície granulosa ou papilosa.
Bibliografia básica - Baker (1870), Hooker (1843), Kramer (1978), Raddi (1825), Sehnem (1972), Swartz (1817), R. Tryon (1986), R. Tryon \& A. Tryon (1982).

\section{Adiantum $\mathrm{L}$.}

Plantas terrestres. Caule curto a longo-reptante, com escamas. Frondes monomorfas, eretas a patentes, cespitosas ou espaçadas; lâmina 1-4-pinada, deltóide a helicoidal, glabra ou pubescente, indumento formado por escamas e/ou tricomas; venação geralmente livre, nervuras simples ou furcadas, ou nervuras anastomosadas, sem vênulas livres inclusas nas aréolas. Soros curtos ou alongados, marginais, com indúsio formado pela margem da lâmina recurvada e modificada.

\section{Chave para as espécies}

1. Pecíolo anguloso; lâmina subcoriácea a coriácea; segmentos não articulados 1. A. sinuosum

1'. Pecíolo cilíndrico; lâmina cartácea; segmentos articulados 2. A. subcordatum

1. Adiantum sinuosum Gardner in Hook., Icon. pl. v. 6 , t. 504.1843.

Figs.: 1-2.

\footnotetext{
' Trabalho feito conforme o planejamento apresentado por Giulietti et al. (1987).
} 
Caule curto, c. 0,5 cm diam., com escamas estreitolanceoladas, castanho-alaranjadas, margem inteira. Frondes c. $25 \mathrm{~cm}$ compr. e c. 8,0 cm larg., eretas; pecíolo delgado, anguloso, c. 0,1 cm diam., castanho-escuro a negro, glabro; lâmina 3-pinada, subcoriácea a coriácea, glabra, verde na face abaxial; raque castanhoescura a negra, glabra, angulosa; pinas 2-pinadas; últimos segmentos subtrapeziformes a rômbicos, 1,0-2,0 cm compr. e 0,6-2,0 cm larg., segmentos contínuos com o peciólulo; venação livre, nervuras simples ou furcadas, terminação na margem dos segmentos. Soros marginais, dispostos em ambas as margens dos segmentos, exceto na base; indúsio fortemente reniforme.

Material examinado: Santana do Riacho, Serra do Cipó, a $1600 \mathrm{~m}$ de alt., col. E. Pereira \$873, 15.III.1964 (HB).

Trata-se de uma espécie endêmica do Brasil Central. Ocorre geralmente em solo arenoso-pedregoso entre afloramentos rochosos. Até o presente momento foi encontrada nos estados de Mato Grosso, Goiás e Minas Gerais.

Adiantum sinuosum caracteriza-se pelas escamas do caule castanho-alaranjadas e indúsio fortemente reniforme, formado pela margem da lâmina recurvada $e$ modificada.

2. Adiantum subcordatum Sw., Sv. Vet..-Akad. Handl.: 75. 1817.

Adiantum truncatum Raddi, Pl. bras. nov. gen.: 59, t.78 f.1. 1825.

Figs.: 3-4.

Caule longo-reptante, c. 0,5 cm diam., com escamas lanceoladas, castanho-escuras, margem inteira. Frondes $40,0-80,0 \mathrm{~cm}$ compr. e 20,0-40,0 cm larg., eretas a patentes; pecíolo robusto, cilíndrico, c. $0,5 \mathrm{~cm}$ diam., castanho-escuro a negro, glabro, brilhante; lâmina 3-4-pinada, cartácea, glabra, glauca na face abaxial; raque castanho-escura a negra, glabra, cilíndrica; pinas 2-3pinadas; últimos segmentos subcordiformes, deltóides ou rômbicos, 2,5-8,0 cm compr. e 2,0-4,0 cm larg., segmentos articulados com o peciólulo; venação livre, nervuras simples ou furcadas, terminações no interior de dentes na margem dos segmentos. Soros marginais, dispostos em ambas as margens do segmento, exceto na base e no ápice, pequenos; indúsio semilunar.

Material examinado: Santana do Riacho, Rodovia Belo Horizonte-Conceição do Mato Dentro: Mãe d'água, CFSC 7595, col. J. R. Pirani et al., 08.X.1981. (HRCB, SP, SPF). Idem, id., Córrego Véu da Noiva, CFSC 11467, col.J. R. Pirani E M. C. Bonfim ., 21.V.1989 (SPF). Idem, id., na estrada para Lapinha, CFSC 7883, col. C. F. Muniz et al., 18.II.1982 (HRCB, SP, SPF). Idem, id., Parque Nacional da Serra do Cipó, Cachoeira da Farofa, CFSC 10237, col. J. Prado et al. s.n. 13.VII.1987 (SPF). Id., id, antigo Km 110, Chapéu de Sol, col. J. Prado et al. 100, 20.II.1987 (SPF).

Adiantum subcordatum caracteriza-se por apresentar rizoma longo-reptante, frondes grandes $(80 \mathrm{~cm}$ compr.), glaucas na face abaxial, últimos segmentos variando de subcordiformes, deltóides a rômbicos, pecíolo, raque e peciólulo castanho-escuros a negros, glabros, brilhantes e pelos segmentos articulados com o peciólulo.

Na Serra do Cipó, ocorre no interior de matas-degaleria, c. de $1000 \mathrm{~m}$ de altitude, em locais úmidos e sombreados.

Trata-se de um táxon com distribuição restrita ao Brasil, tendo sido encontrado até o momento nos seguintes Estados: Minas Gerais, Rio de Janeiro, São Paulo, Paraná e Santa Catarina.

\section{Taenitidoideae (C. Presl) R. M. Tryon}

Caule, na maioria dos gêneros, com tricomas ou cerdas, raramente com escamas. Segmento fértil sem margem modificada em indúsio. Soros ao longo das nervuras livres, às vezes com paráfises; esporos geralmente com uma ou mais flanges equatoriais e outras cristas proeminentes ou tubérculos.

Bibliografia básica - Baker (1870), Copeland (1947), Prado (1995), Sehnem (1972), Swartz (1817), A. Tryon (1970), R. Tryon (1986), R. Tryon \& A. Tryon (1982).

\section{Eriosorus Fée}

Eriosorus myriophyllus (Sw.) Copel., Gen. fil.: 58. 1947. Gymnogramma myriophylla Sw., Sv. Vet.-Akad. Handl.: 58. 1817.

Figs.: 5-6.

Caule horizontal, c. $0,5 \mathrm{~cm}$ diam., com cerdas articuladas, castanho-escuras, brilhantes. Frondes 8,0-50,0 $\mathrm{cm}$ compr. e 2,5-10,0 cm larg., eretas a escandentes; pecíolo sulcado na face adaxial, c. $0,1 \mathrm{~cm}$ diam., castanho-avermelhado a negro, com tricomas; lâmina alongado-triangular, truncada na base, 2-3-pinado-pinatífida, cartácea, delgada, com tricomas glandulares nas duas superfícies; raque castanho-escura, com tricomas glandulares; pinas pinatífidas a pinatissectas; últimos segmentos emarginados e com margem plana; nervuras simples ou furcadas. 


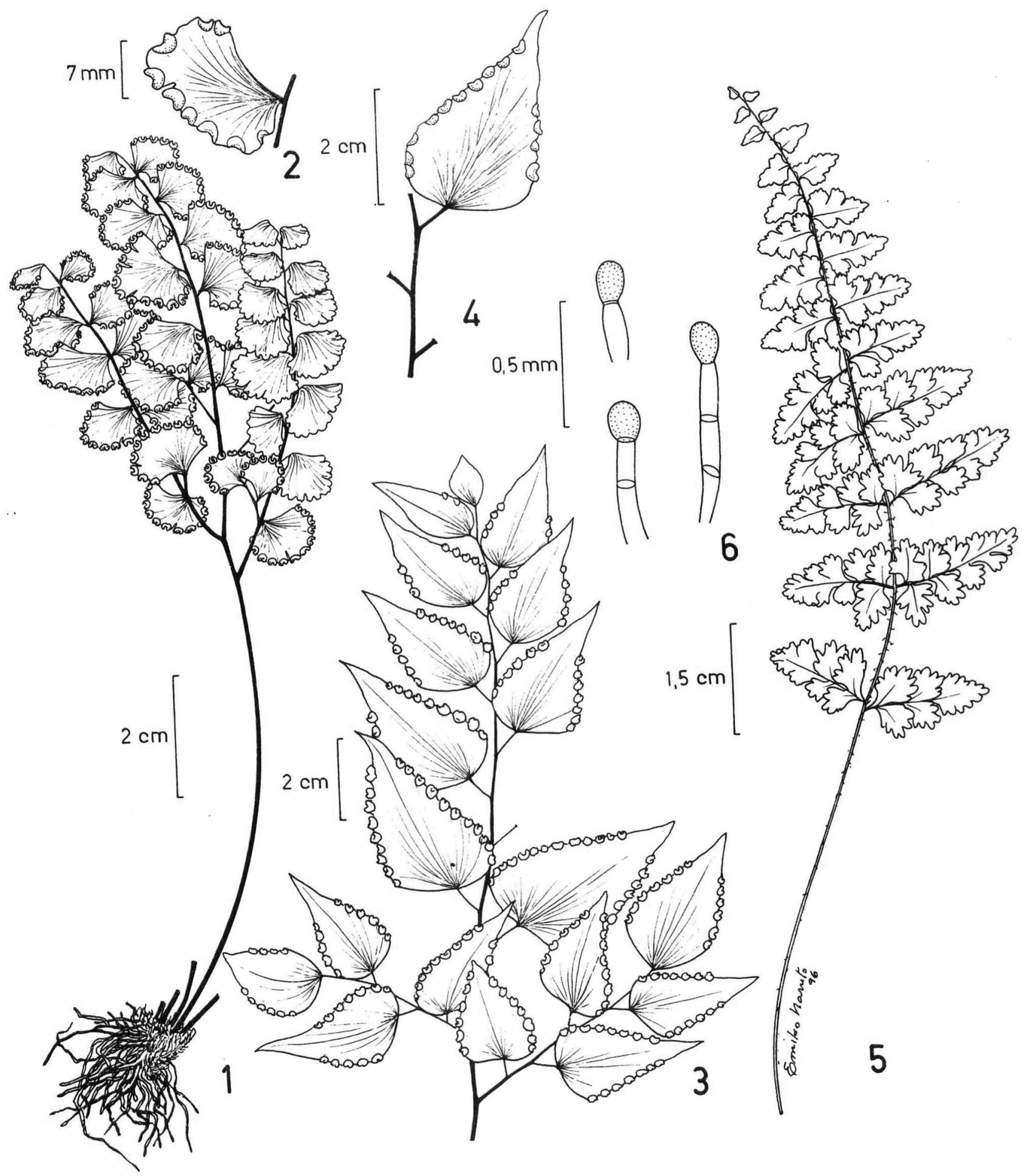

Figs. 1-2-Adiantum sinuosum Gardner, 1-Hábito; 2-Pínula. Figs. 3-4-Adiantum subcordatum Sw., 3-Parte da fronde; 4-Pínula. Figs. 5-6-Eriosorus myriophyllus (Sw.) Copel., 5-Fronde; 6-Tricomas da raque.

Figs. 1-2-Adiantum sinuosum Gardner, 1-Habit; 2-Pinnule. Figs. 3-4-Adiantum subcordatum Sw., 3-Part of the frond; 4-Pinnule. Figs. 5-6-Eriosorus myriophyllus (Sw.) Copel., 5-Frond; 6- Rhachis' trichomes. 
Material examinado: Santana do Riacho, Estrada Lagoa Santa-Conceição do Mato Dentro, Parque Nacional da Serra do Cipó, pr. ao IBDF, caminho para Salitreira, CFSC 10228, col. J. Prado et al. s.n. (SPF). Idem, id., km 140, CFSC 4619, 4620, col. A. B. Joly et al. s.n., 20.X.1973 (SP). Serra do Cipó, col. A. C. Brade 14398, s.d. (BM).

Distribui-se pelos estados de Minas Gerais, Rio de Janeiro, São Paulo, Paraná, Santa Catarina e Rio Grande do Sul, chegando até o Uruguai (Cerro Largo) (A. Tryon 1970).

De acordo com A. Tryon (1970) é uma espécie com uma ampla tolerância ecológica, com plantas ocorrendo tanto em locais úmidos quanto secos (ambientes xéricos), numa altitude que pode variar de 600 até 2300 metros.

Na Serra do Cipó, cresce em fendas de rochas, em locais parcialmente protegidos ou entre gramíneas, em barrancos à margem de estrada.

Eriosorus myriophyllus caracteriza-se pela lâmina pubescente, cartácea, segmentos com a margem plana e ápice emarginado.

Eriosorus sellowianus (Mett. ex Kuhn) Copel. é uma espécie próxima que geralmente é confundida $\operatorname{com} E$. myriophyllus, porém distingue-se por apresentar a lâmina coriácea, ereta e pelos segmentos com margem fortemente revoluta e recortada. Na revisão do gênero, A. Tryon (1970) refere a coleta de Brade 14398 (BM), proveniente da Serra do Cipó, como sendo $E$. sellowianus, mas este material é claramente E. myrio- phyllus. E. sellowianus ocorre no Pico do Itambé e na porção sul da Cadeia do Espinhaço em Ouro Preto, Serra da Piedade e na Serra de Ibitipoca, em altitudes de 1450-1900 m.

\section{Referências}

BAKER, J.G. 1870. Cyatheaceae \& Polypodiaceae. In C.F.P. Martius \& A. G. Eichler (eds.), Flora brasiliensis 1(2):305-362.

COPELAND, E.B. 1947. Genera filicum, the genera of ferns. 247 p. 10 tab. Waltham Mass.: Chronica Botanica.

GIULIETTI, A.M., MENEZES, N.L., PIRANI, J.R., MEGURO, M. \& WANDERLEY, M.G.L. 1987. Flora da Serra do Cipó, Minas Gerais: Caracterização e lista das espécies. Bot. Bot. Univ. São Paulo, 9:1-151.

HOOKER, J. W. 1843. Icones plantarum v.6. William Pamplin. London.

KRAMER, K. U. 1978. The pteridophytes of Suriname. Uitgaven Natuurwetensch. Studiekring Suriname Ned. Antillen, Natuurhist. Reeks 93:1-198.

PRADO, J. 1995. Ferns. In B. L. Stannard (ed.) Flora of the Pico das Alinas, Chapada Diamantina - Bahia, Brazil. Whitstable Litho. Ltd. Whitstable, Kent. p.79-80, 85-110.

RADDI, G. 1825. Plantarum brasiliensium, nova genera et species novae, vel minus cognitae collegit, et descripsit Iosephus Raddius I. (Filices). 101 p. 84 tab. Florentiae.

SEHNEM, A. 1972. Pteridáceas. In R. Reitz (ed.) Flora Ilustrada Catarinense. 243p. Herbário Barbosa Rodrigues, Itajaí, SC.

SWA RTZ, O. 1817. Nya arter af ormbunkar (Filices) från Brasilien. Sv. Vet.-Akad. Handl. p:58-75, 4 tab.

TRYON, A. F. 1970. A monograph of the fern genus Eriosorus. Contr. Gray Herb. 200:54-174.

TRYON, R. M. 1986. Some new names and combinations in Pteridaceae. Amer. Fern J. 76(4):184-186.

TRYON, R.M. \& TRYON, A.F. 1982. Ferns and allied plants, with special reference to Tropical America. 857p. Springer Verlag. New York. 